\title{
Latrine coverage and its utilization in rural areas of Telangana: A community based cross sectional study
}

\author{
Ramesh Palabindela ${ }^{1}$, M Vijay Kumar $^{2 *}$, Greeshma Peddinti ${ }^{3}$, Nikitha Chellapuram ${ }^{4}$ \\ ${ }^{1}$ Assistant Professor, Department of Community Medicine, Government Medical College, Suryapet, Telangana, INDIA. \\ ${ }^{2}$ Assistant Professor, Department of Community Medicine, Gandhi Medical College, Secunderabad, Telangana, INDIA. \\ ${ }^{3} 3$ rd year MBBS Student, Bhaskar Medical College, Yenkapally, Moinabad, Rangareddy District, Telangana, INDIA. \\ ${ }^{4}$ Duty Medical Officer, Satya Kidney Center and Super specialty Hospital, Himayatnagar, Hyderabad, Telangana, INDIA. \\ Email: vijaykmbbs@gmail.com
}

Abstract Background: Sanitation refers to the provision of facilities and services for the safe management of human excreta from the toilet to containment and storage and treatment onsite or conveyance, treatment and eventual safe end use or disposal. Material and Methods: A community based cross sectional study was conducted in rural areas of Rangareddy District, Telangana under rural field practice area of the medical college. A total of 100 households were selected by convenient sampling technique from selected village. From the selected household, information was collected from the informant by using a modified WHO questionnaire. Results: With regards to presence of latrine at home, in 90 households latrine was present and in rest 10 households there was no latrine. Open defecation was noted in 14\%. Reasons for construction of latrine was elicited which showed self-initiation as major reason in $72 \%$ cases followed by health workers advice in $16 \%$. Among those who had latrine at home but still opting for open defecation reasons were elicited. $8 \%$ felt that open air defecation is better than latrine at home and few mentioned that maintenance of latrine was difficult hence opted for open air defecation. Conclusion: In majority of the households, there was presence of latrine and people were using it. In houses with no latrine, economical constraints were noted as major barriers in construction of latrine which needs to be addressed as provision of financial assistance from Government and its proper implementation.

Key Words: latrine, utilization, coverage, reasons, open defecation

*Address for Correspondence:

Dr. M.Vijay Kumar, H.No 12-5-106/3A, Sardar Patel Nagar, Near Rita School, Bharat Nagar, Hyderabad, Telangana State.

Email: vijaykmbbs@gmail.com

Received Date: 19/11/2019 Revised Date: 12/12/2019 Accepted Date: 02/01/2020

DOI: https://doi.org/10.26611/10111311

\begin{tabular}{|l|l|}
\hline \multicolumn{2}{|c|}{ Access this article online } \\
\hline Quick Response Code: & Website: \\
\hline & www.medpulse.in \\
\hline
\end{tabular}

\section{INTRODUCTION}

Human excreta is a source of infection and definitely an important cause of environmental pollution. Hence, safe removal and disposal is most important aspect in preventing many diseases. Poor management of excreta is associated to transmission of diseases such as cholera, diarrhoea, dysentery, hepatitis A, typhoid and polio, and also contributes to malnutrition. As per World Health Organization (WHO) factsheets on sanitation, Inadequate sanitation is estimated to cause 4,32,000 diarrhoeal deaths annually and is a major factor in several neglected tropical diseases, including intestinal worms, schistosomiasis, and trachoma. 2.0 billion people still do not have basic sanitation facilities such as toilets or latrines. Of these, 673 million still defecate in the open, for example in street gutters, behind bushes or into open bodies of water ${ }^{1}$. Sanitation refers to the provision of facilities and services for the safe management of human excreta from the toilet to containment and storage and treatment onsite or conveyance, treatment and eventual safe end use or disposal. Access to safe and clean drinking water and sanitation is recognized as Human 
Right in the United Nations General Assembly 2010 and called for an international efforts to help countries to provide safe, clean, accessible and affordable drinking water and sanitation ${ }^{2}$. With more than two thirds of Indian population living in rural areas, the problem of open defecation and lack and underutilization of facilities are considered major barriers. Though open defecation practices have scaled down but still it persists especially in rural areas. The problem has thick deep roots with a multi factorial origin consisting of social and cultural factors. When large number of people are defecating outside, it's extremely difficult to avoid ingesting human waste either because it has contaminated food or water supplies. ${ }^{3}$ Situation has definitely improved over the decades especially after the "The Swachh Bharat Campaign" launched by Government of India. The aim of Swachh Bharat Mission (Gramin) is to achieve a clean and Open Defecation Free (ODF) India by 2nd October, 2019. ${ }^{4}$ As per the Government estimates, there are currently 699 open defecation free districts, 5,99,963 open defecation free villages and $63.3 \%$ of rural population practicing Solid and Liquid Waste Management (ODF Plus). ${ }^{5}$ Sustainable Development Goal target 6.2 calls for adequate and equitable sanitation for all. The target is tracked with the indicator of "safely managed sanitation services" - use of an improved type of sanitation facility that is not shared with other households and from which the excreta produced are either safely treated in situ, or transported and treated offsite. Ending open defecation is an indicator being used to measure towards the sustainable development goals. Extreme poverty and lack of sanitation are statistically linked. Therefore eliminating open defecation is thought to be an important part of the effort to eliminate poverty ${ }^{6}$.The present study which aims to determine the coverage of toilets in the village and its utilization which would serve to provide insights which can be addressed to improve the rural sanitation.

\section{METHODOLOGY}

A community based cross sectional study was conducted in rural areas of Rangareddy District, Telangana under the rural field practice area of the medical college. Study duration was six months from February to July 2018.

\section{Sample size:}

Sample size estimation was derived using the formula $4 \mathrm{pq} / 12$, where $\mathrm{p}$ is prevalence, $\mathrm{q}$ is $100-\mathrm{p}$ and 1 is allowable absolute error. In the present study, $p$ is taken from the percentage of households with having access to improved toilet facility from District Level Household Survey (DLHS -4) which is $50.5 \%$ from rural areas of Rangareddy District, Telangana State ${ }^{7}$. After substituting the prevalence as $50.5 \%, \mathrm{q}$ as $49.5 \%$ and 1 as absolute error of $10 \%$, final sample size obtained was 100 . Out of the villages under the rural field practice area, one village was selected by lottery method and from the selected village, 100 households were selected by convenient sampling technique. Informed verbal consent was taken from the study participants prior to the start of the study. From the selected household, information was collected from the informant by using a pre designed pre tested questionnaire. Modified WHO questionnaire (WHO Library Cataloguing-in-Publication Data, Core questions on drinking-water and sanitation for household surveys) ${ }^{8}$ was used for assessing sanitation conditions.

\section{Statistical Analysis:}

Data entry was done using Microsoft Excel 2010 version and analysis using EPI INFO version 7. Interpretation of data was done using graphs, percentages and proportions.

\section{RESULTS}

\section{Socio-demographic factors:}

The mean age of the respondents was $34.86 \pm 13.88$ years with majority (63\%) being in $31-40$ years age group. More than three fourth of the respondents were Hindu by religion followed by Muslims and Christians. Almost half the proportions belonged to lower middle class as per modified BG Prasad socio economic classification. The mean number of members in the households were five. Out of the 100 households, majority (58\%) had pucca houses followed by semi pucca houses in 36\%. 6 houses were kutcha houses.

\section{Characteristics of latrine facilities and Utilization:}

With regards to presence of latrine at home, in 90 households latrine was present and in rest 10 households there was no latrine. Open defecation was noted in $14 \%$. Reasons for construction of latrine was elicited which showed self-initiation as major reason in $72 \%$ cases followed by health workers advice in $16 \%$. Few also mentioned pressure from family members also as a reason. In $82.2 \%$ cases, type of latrine was pour flush type followed by direct pit in $17.8 \%$. And in majority (76.7\%), years since the construction of latrine was more than two years. About three fourth (72.3\%) mentioned that they cleaned latrine every day and four households mentioned they rarely cleaned latrine. In $87.7 \%$, adequate privacy was present and in $22.2 \%$ they had to share latrine facility with other households. Among those who had latrine at home but still opting for open defecation reasons were elicited. $8 \%$ felt that open air defecation is better than latrine at home and few mentioned that maintenance of latrine was difficult hence opted for open air defecation. Reasons were also elicited in the households where there was no latrine. About 10\% mentioned lack of money as the major reason for not constructing latrine. Few other reasons mentioned were 
lack of space, nuisance from smell. Majority of those who opted for open defecation were not aware of the consequences and diseases spread due to open defecation. With regards to hand washing practices, majority (92\%) washed their hands after defecation. Among them majority $(82 \%)$ used either soap or hand wash for cleaning their hands and $8 \%$ used only water for cleaning.

Table 1: Characteristics of Latrine facilities

\begin{tabular}{|c|c|c|}
\hline Characteristic & Number & Percentage \\
\hline \multicolumn{3}{|l|}{ Presence of Latrine $(n=100)$} \\
\hline Yes & 90 & $90 \%$ \\
\hline No & 10 & $10 \%$ \\
\hline \multicolumn{3}{|l|}{ Type of latrine $(n=90)$} \\
\hline Pour flush & 74 & $82.2 \%$ \\
\hline Direct pit & 16 & $17.8 \%$ \\
\hline \multicolumn{3}{|l|}{ Year since Latrine constructed } \\
\hline$<2$ years & 21 & $23.3 \%$ \\
\hline$\geq 2$ years & 69 & $76.7 \%$ \\
\hline \multicolumn{3}{|l|}{ Frequency of Latrine cleaning } \\
\hline Everyday & 65 & $72.3 \%$ \\
\hline Often & 21 & $23.3 \%$ \\
\hline Rarely & 04 & $4.4 \%$ \\
\hline \multicolumn{3}{|l|}{ Closure for privacy } \\
\hline Yes & 79 & $87.7 \%$ \\
\hline No & 11 & $12.3 \%$ \\
\hline \multicolumn{3}{|c|}{$\begin{array}{l}\text { Sharing latrine facility with other } \\
\text { households }\end{array}$} \\
\hline Yes & 20 & $22.2 \%$ \\
\hline No & 70 & $77.8 \%$ \\
\hline
\end{tabular}

\section{DISCUSSION}

Rural sanitation had different social aspects which might have an impact on utilization of Latrines even if facilities are available. The present community based cross sectional study had been done to determine this aspect of latrine utilization and its factors. In the present study, majority of the households $(90 \%)$ had sanitary latrine with $14 \%$ open defecation being noted. A similar kind of study by Sheethal MP, Shashikantha $\mathrm{SK}^{9}$ in Southern Karnataka observed a slightly higher percentage of open air defecation at $18 \%$ and $82 \%$ households having sanitary latrine. The difference in these findings compared to present study might be due to study settings being different geographical locations. In $10 \%$ of the households wherein there was no latrine, reasons elicited found lack of money as a major barrier for construction followed by lack of space and nuisance of smell. In concurrence to the present study findings, study by Sheethal MP, Shashikantha $\mathrm{SK}^{9}$ found that though they were aware about financial assistance, the most common reasons for not obtaining financial benefits were lack of space (22\%), delayed sanction of money (19\%), comfortable with open air defecation $(11 \%)$, no own house $(9 \%)$ and lack of water supply $(9 \%)$. A community based cross sectional study on use of sanitary latrines in a rural set up of Maharashtra observed that in spite of presence of community latrines, $67 \%$ of the population resorted to open air defecation. Inadequate water was the major reason for underutilization $(48.6 \%)$ of community latrines followed by lack of awareness about the availability of these (19.5\%). Only $14.5 \%$ were not aware of any harmful effect of open air defecation. $66.7 \%$ of them had the knowledge of night soil disposal. $77.6 \%$ were aware of the importance of hand washing with regards to prevention of disease..$^{10}$ Hand hygiene practices after defecation is extremely important to maintain proper hygienic conditions. In the present study, majority (92\%) washed their hands after defecation. Among them majority $(82 \%)$ used either soap or hand wash for cleaning their hands and $8 \%$ used only water for cleaning. In contrast to the present study findings, study by Yimam YT et al ${ }^{11}$ from rural areas of Northwest Ethiopia et al found hand washing facilities and practices was very poor. Study by Molla Gedefaw et al ${ }^{12}$ from Ethiopia on opportunities and challenges of latrine utilization found that the current level of proper latrine utilization was fairly good in the rural communities. About $80 \%$ of study participants claimed that they constructed latrines following advice from health extension workers which was also noted in the present study (16\%). Hence, the present study findings were in concurrent with other studies in majority aspects. Though the provision of providing financial assistance for construction of toilets is present, but majority were not receiving financial assistance. Hence the implementation of the scheme needs to be addressed so that people can construct toilets and use them and ultimately making Open Defecation free villages. Limitations of the study: The present study findings throw a highlights of only village, similar kind of studies on larger scale would be required to get an true estimate of the picture. Small sample and convenient sampling technique limits the generalizability of the findings. Qualitative aspects have not been done in the present study which could have brought in other important aspects.

\section{CONCLUSIONS}

In majority of the households, there was presence of latrine and people were using it. Open defecation was observed in the study with reasons being difficulty in maintenance and subjective feeling of open air defecation considered better than latrine at home. In houses with no latrine, economical constraints were noted as major barriers in construction of latrine which needs to be addressed as provision of financial assistance from Government and its proper implementation. 


\section{REFERENCES}

1. WHO Fact sheet on Sanitation. Accessed from https://www.who.int/news-room/factsheets/detail/sanitation (Last accessed on 15-11-19)

2. WHO and UNICEF (2019). Updated estimated on household drinking water, sanitation and hygiene. Accessed from https://washdata.org/data/household\#!/ind. (Last accessed on 18-10-19)

3. WHO and UNICEF(2017). Progress on drinking water, sanitation and hygiene:2017 update and SDG guidelines.

4. Government of India. Swachh Bharat Mission-Gramin. Department of Drinking water and Sanitation. Ministry of Jal Shakti. Accessed from https://swachhbharatmission.gov.in/SBMCMS/aboutus.htm (Last accessed on 16-11-19)

5. National Annual Rural Sanitation Survey (NARSS) 2018-19. Department of Drinking water and Sanitation. Ministry of Jal Shakti. Available from the following PDF link: http://sujalswachhsangraha.gov.in/sites/default/files/NARSS-201819.pdf (last accessed on 14-11-19)

6. Molla Gedefaw, Yibeltal Amsalu, Molalign Tarekegn, Worku Awoke. Opportunities, and Challenges of Latrine Utilization among Rural Communities of Awabel District, Northwest Ethiopia. Open Journal of Epidemiology 2015;5:98-106.

7. International Institute for Population Sciences. District Level Household and facility Survey, DLHS-4, District Fact Sheet, Rangareddy (2012-2013).
8. WHO/UNICEF Joint Monitoring Programme for Water Supply and Sanitation (JMP).Core questions on drinkingwater and sanitation for household surveys. Available from the following link:

https://www.who.int/water_sanitation_health/monitoring/ oms brochure core questionsfinal24608.pdf (last accessed on 10-08-19)

9. Sheethal MP, Shashikantha SK. A cross-sectional study on the coverage and utilization of sanitary latrine in rural field practice area of a tertiary care hospital in Southern Karnataka. Int $\mathrm{J}$ Community Med Public Health 2016;3:1540-3

10. Anu Bhardwaj, Avinash Surana, Prassana Mithra, Abhishek Singh, Sanjeet Panesar, Pankaj Chikkara. A Community based cross sectional study on use of sanitary latrines in a rural setup in Maharashtra. Healthline 2013;4(1):89-93.

11. Yimam YT, Gelaye KA, Chercos DH. Latrine utilization and associated factors among people living in rural areas of Denbia district, Northwest Ethiopia, 2013, a crosssectional study. Pan Afr Med J. 2014 Aug 26;18:334.

12. Budhathoki, S.S., Shrestha, G., Bhattachan, M. et al. Latrine coverage and its utilisation in a rural village of Eastern Nepal: a community-based cross-sectional study. BMC Res Notes 10, 209 (2017) doi:10.1186/s13104-0172539-3.

Source of Support: None Declared Conflict of Interest: None Declared 